\title{
UMA COLEÇ̃̃o ICTIOLÓGICA PROVENIENTE DE ATIVIDADE PESQUEIRA DA SOCIEDADE AWÁ-GUAJÁ DO ESTADO DO MARANHÃO
}

\author{
AN ICTIOLOGICAL COLLECTION FROM FISHERIES ACTIVITY BY THE AWÁ-GUAJÁ SOCIETY OF THE STATE \\ OF MARANHÃO
}

UNA COLECCIÓN ICTIOLÓGICA DE LA ACTIVIDAD PESQUERA POR LA SOCIEDAD AWÁ-GUAJÁ DEL ESTADO
DE MARANHÃO

Artur Chahud ${ }^{1}$

Mercedes Okumura ${ }^{2}$

\section{Resumo}

Os Awá-Guajá representam um dos últimos povos caçadores-coletores do mundo e atualmente vivem em reservas indígenas localizadas ao noroeste do Estado do Maranhão, Brasil. A “Coleção Etnográfica Guajá” é uma coleção de remanescentes faunísticos oriundos de uma escavação das lixeiras dessa sociedade acumuladas ao longo de três anos, no período de 1987 a 1990. O material osteológico coletado inclui grande quantidade de vertebrados terrestres e de restos de peixes, estes últimos são resultado de atividades pesqueiras desse grupo. Observando que os Awá-Guajá possuíam pouca ou nenhuma predileção clara por determinada espécie, o material coletado pode acrescentar importantes informações ecológicas e da biodiversidade da Amazônia da época. Além disso, por ser uma comunidade tradicional o conhecimento obtido poderá auxiliar no esclarecimento de depósitos ictiológicos em sítios arqueológicos antigos encontrados no interior do Brasil e próximos a sistemas fluviais.

Palavras chave: Siluriformes, Characiformes, Taxonomia, Tafonomia, Amazônia.

\begin{abstract}
The Awá-Guajá represent one of the last hunter-gatherer societies in the world and, currently, live in indigenous reserves in the northwest of the State of Maranhão, Brazil. The "Guajá Ethnographic Collection" is a collection of fauna remains from an excavation of the "dumps" of this society accumulated over three years, from 1987 to 1990. The osteological material collected includes a large quantity of terrestrial vertebrates and fish remains; the latter are the result of fishing activities by that

1 Laboratório de Estudos Evolutivos Humanos, Departamento de Genética e Biologia Evolutiva, Instituto de Biociências, Universidade de São Paulo, Rua do Matão 277, São Paulo, SP 05508-09o. E-mail: arturchahud@yahoo.com

ORCID: https://orcid.org/oooo-ooo1-7690-3132

2 Laboratório de Estudos Evolutivos Humanos, Departamento de Genética e Biologia Evolutiva, Instituto de Biociências, Universidade de São Paulo, Rua do Matão 277, São Paulo, SP 05508-09o. E-mail: okumura@ib.usp.br

ORCID: https://orcid.org/oooo-ooo2-1894-6430
\end{abstract}


group. Observing that the Awá-Guajá had little or no clear predilection for a given species, the material collected can add important ecological and biodiversity information from the Amazon of the time. In addition, because it is a traditional community, the knowledge obtained may help to clarify ichthyological deposits in ancient archaeological sites found in the interior of Brazil and close to river systems.

Keywords: Siluriformes, Characiformes, Taxonomy, Taphonomy, Amazon.

\section{Resumen}

Los Awá-Guajá representan uno de los últimos pueblos cazadores-recolectores del mundo y actualmente viven en reservas indígenas ubicadas en el noroeste del estado de Maranhão, Brasil. La "Colección Etnográfica Guajá" es una colección de restos de fauna recuperada de una excavación de los vertederos de esta sociedad acumulados durante tres años, de 1987 a 1990. El material osteológico recolectado incluye una gran cantidad de vertebrados terrestres y restos de peces, estos últimos son el resultado de las actividades pesqueras de ese grupo. Es posible observar que los Awá-Guajá tenían poca o ninguna predilección clara por una determinada especie de pez. Ese material recolectado puede agregar información ecológica y de biodiversidad importante de la Amazonía de la época. Además, debido a que es una comunidad tradicional, el conocimiento obtenido en nuestro estudio puede ser útil para la discusión sobre depósitos ictiológicos en yacimientos arqueológicos antiguos encontrados en el interior de Brasil y cerca de sistemas fluviales.

Palabras clave: Siluriformes, Characiformes, Taxonomía, Tafonomía, Amazonia.

\section{INTRODUÇÃO}

A comunidade Awá-Guajá é um dos últimos povos caçadores-coletores de hábito nômade da Amazônia, embora atualmente vivam em reservas indígenas. Os primeiros contatos foram realizados entre os anos de 1950 e 1960 e durante esse período o grupo passou de poucas dezenas de indivíduos para algumas centenas. Desde a década de 1980, os Awá-Guajá se distribuem em três Terras Indígenas principais, dentro das quais existem cinco comunidades aldeadas pela Fundação Nacional do Índio (FUNAI). As reservas são: Alto Turiaçu (530.525 ha), Caru (172.667 ha) e Awá (118.0oo ha).

A Coleção Etnográfica Guajá é uma coleção de remanescentes faunísticos oriunda da reserva Caru, acumuladas ao redor do acampamento indígena (Queiroz e Kipnis, 1990). Embora essa coleção seja rica em material osteológico de diversos grupos de vertebrados, poucos trabalhos foram realizados até o momento (Queiroz e Kipnis, 1990; Forline, 1997; Prado, 2007; Bissaro-Junior, 2008; Prado et al. 2012; Chahud, 2019; 2020a; 2020b). Assim, existe vasto potencial de análise desses 
materiais sob diferentes abordagens, incluindo abordagem etnográfica e zoológica, entre outras.

Em análises sobre as atividades de subsistência com os Awá-Guajá realizadas por Forline (1997) e Prado et al. (2012) nas reservas Alto Turiaçu, Awá e Caru nos anos de 1992-1994, verificou-se que os peixes representavam a principal fonte de subsistência de toda comunidade durante os períodos secos. A pesca já era praticada pelos Awá-Guajá, porém passou a ser um hábito mais frequente com a estabilização nas terras indígenas. No passado, havia disputas de áreas ribeirinhas com colonos e outras comunidades indígenas, assim a localização atual da reserva indígena próxima a cursos fluviais facilitou a atividade pesqueira.

O objetivo dessa contribuição é a apresentação dos restos de peixes provenientes de atividade pesqueira do Awá-Guajá entre os anos de 19871990, a caracterização tafonômica do material osteológico e a discussão sobre a biodiversidade ictiológica da região. Ainda, almejamos desenvolver hipóteses que possam ser aplicadas em sítios arqueológicos de ambientes tropicais úmidos sob influências fluviais.

\section{MATERIAL E MÉTODOS}

O material faunístico refere-se ao consumo dos índios da Terra Indígena Caru, às margens do Rio Pindaré, no Estado do Maranhão, Brasil (Fig. 1) e coletado no ano de 1990. Todo material faunístico estava enterrado em lixeira feita pelos AwáGuajá ou em superfície nas proximidades de suas habitações e locais de preparo desses animais. Segundo Queiroz e Kipnis (1990), o material coletado corresponde às atividades de caça realizadas imediatamente após a mudança para a Terra Indígena Caru no ano de 1987.

A coleção inclui milhares de ossos de mamíferos, répteis, aves e peixes, que estão depositados e catalogados no Laboratório de Estudos Evolutivos Humanos do Departamento de Genética e Biologia Evolutiva do Instituto de Biociências da Universidade de São Paulo (LEEH-IB-USP). 


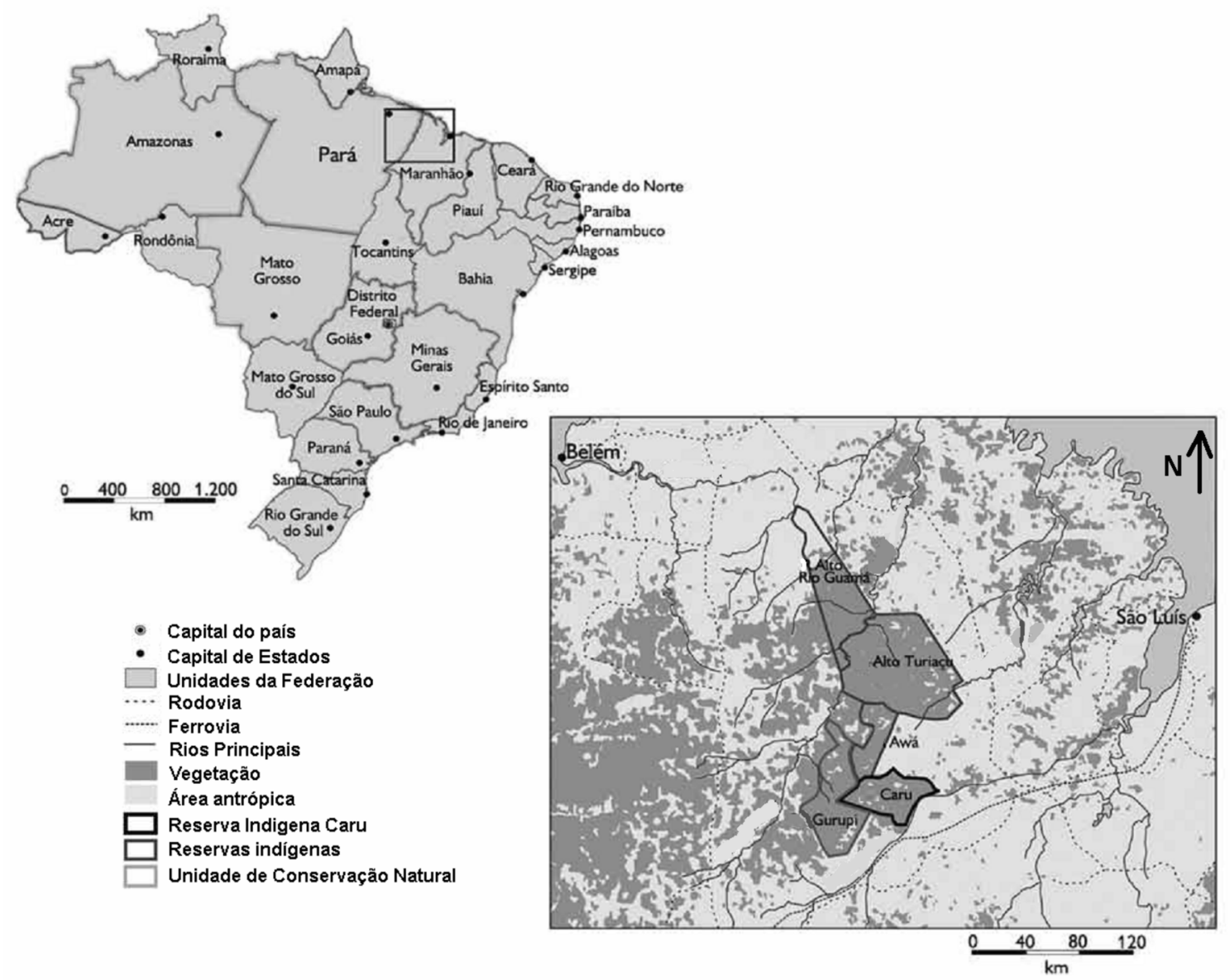

Figura 1. Localização das reservas indígenas Awá-Guajá no Estado do Maranhão. Adaptado de Prado et al. (2012).

\section{DADOS CLIMÁTICOS}

O clima da região das reservas indígenas Awá-Guajá é considerado Bz úmido, segundo a classificação Thornthwaite (1948), que leva em consideração os fatores entre evapotranspiração e precipitação. Nessa classificação, a região estaria entre 40 para 6o MI (índice de umidade), sendo que em climas sub-úmidos, áridos e semiáridos ( $C_{2}$, D e E), os valores são negativos e no superúmido (A) é superior a 100.

A coleta de todo o material da Coleção Guajá foi realizada entre os meses de agosto e setembro de 1990. Segundo Reschke et al. (2011), as características hídricas para a região indicam período seco em julho, com déficit de 426 milímetros entre agosto e dezembro e um período úmido a partir de janeiro, com excedente de 1001 milímetros entre os meses de fevereiro a junho. A partir desses dados é possível inferir que a coleta foi realizada nos primeiros meses do período seco, provavelmente chegando ao clímax desse período no mês de setembro. 


\section{PESCARIA COMO ATIVIDADE DOS AWÁ-GUAJÁ}

As técnicas de pesca eram restritas antes do estabelecimento das terras indígenas, contudo Forline (1997) e Prado et al. (2012) comentam que nas reservas atuais é observada a utilização de venenos para peixes, anzóis, redes, arpões, arco e flecha, canoas, armadilhas, lanternas para pesca noturna e barricadas, sendo parte dos equipamentos fornecidos pela FUNAI.

Forline (1997) comenta que a utilização de veneno para peixe, conhecido como timbó, era comum apenas na estação seca, quando lagos e rios se tornavam menos volumosos, concentrando uma maior quantidade de peixes em uma menor área e aumentando a eficiência do veneno. Forline (op. cit.) comenta que, inicialmente, a utilização de venenos por parte dos Awá-Guajá era exagerada, causando a morte dos peixes, ao invés de apenas atordoá-los. Essa técnica causava o aparecimento de um considerável número de peixes mortos e em decomposição que flutuavam rio abaixo nos dias seguintes à atividade pesqueira.

\section{DIVERSIDADE ICTIOLÓGICA}

A região amazônica possui uma das maiores riquezas de peixes de água doce do mundo. Segundo Castro e Dourado (2011), foram registradas 109 espécies distribuídas em 33 famílias na região oriental da Amazônia. As observações a respeito das atividades de pesca na Terra Indígena Caru feitas diretamente por Forline (1997), Piorski et al. (2003) e as pesquisas realizadas por Castro e Dourado (op. cit.) na região Pindaré/Alto Turiaçu/Caru (onde estão localizadas a três Terras Indígenas) apresentam 25 famílias, citadas na Tabela 1:

Tabela 1. Diversidade ictiológica observada na região Pindaré/Alto Turiaçu/Caru baseada em Forline (1997), Piorski et al. (2003) e Castro e Dourado (2011).

\begin{tabular}{lll}
\hline Classe & Ordem & Família \\
\hline Chondrichthyes & Myliobatiformes & Potamotrygonidae \\
\hline & Beloniformes & Belonidae \\
\cline { 2 - 3 } Carangiformes & Centropomidae \\
\cline { 2 - 2 } & Acestrorhynchidae \\
& Characidae \\
& Curimatidae \\
& Characiformes & Erythrinidae \\
& Hemiodontidae \\
& Prochilodontidae \\
& Serrasalmidae \\
& Triportheidae \\
\hline
\end{tabular}




\begin{tabular}{lll}
\hline Classe & Ordem & Família \\
\hline & Cichliformes & Cichlidae \\
\hline Clupeiformes & Pristigasteridae \\
\hline Cyprinodontiformes & Anablepidae \\
\cline { 2 - 2 } Gymnotiformes & Apteronotidae \\
& Gymnotidae \\
Osteichthyes & Rhamphichthyidae \\
\cline { 2 - 3 } & Serciformes & Sciaenidae \\
\cline { 2 - 2 } & & Aspredinidae \\
& Auchenipteridae \\
& Callichthyidae \\
& Siluriformes & Doradidae \\
& Loricariidae \\
& Pimelodidae \\
\cline { 2 - 2 } & Synbranchidae \\
\hline
\end{tabular}

Tendo como base os supracitados trabalhos de Forline (1997), Piorski et al. (2003) e Castro e Dourado (2011), as principais ordens registradas na região Amazônica do Maranhão são discutidas a seguir, destacando a presença ou não das mesmas na Coleção Etnográfica Guajá.

\section{Ordem Myliobatiformes}

Os únicos peixes cartilaginosos (Chondrichthyes) registrados na região são raias da Ordem Myliobatiformes, representadas pela espécie Potamotrygon motoro (raia olho de pavão). Não há evidência de pesca desses animais pelos Awá-Guajá. O espinho na cauda dessa espécie contém veneno e pode representar perigo para quem a captura, não sendo impossível que esse seja o motivo de sua ausência na Coleção Etnográfica Guajá.

\section{Ordem Clupeiformes}

A espécie Pellona flavipinnis, citada para a região por PIORSKI et al. (2003), tem corpo fino, escamas muito pequenas e tamanho em torno de $30 \mathrm{~cm}$ de comprimento total. Estas características não favorecem a preservação ou reconhecimento se não forem encontrados indivíduos com ossos articulados ou completos. 


\section{Ordem Characiformes}

Peixes exclusivos de água doce dos trópicos das Américas e da África, os Characiformes possuem grande variação morfológica, tamanho, hábitos alimentares e ecológicos. Forline (1997) e Castro e Dourados (2011) registraram na região do Rio Pindaré e na reserva indígena Caru as famílias dessa ordem; Acestrorhynchidae, Characidae, Curimatidae, Erythrinidae, Hemiodontidae, Prochilodontidae, Serrasalmidae e Triportheidae.

A família Acestrorhynchidae é representada pelo gênero Acestrorhynchus, um peixe pequeno muito comum nos rios do Brasil. Para Castro e Dourados (2011), a espécie encontrada seria $A$. lacustris, porém tal espécie é típica dos estados ao sul do Brasil (Silva e Goitein, 2009). A espécie $A$. falcirostris teria sido registrada por Forline (1997), porém essa identificação também pode não estar correta, pois segundo Gonzalez (2015) as espécies presentes no Rio Pindaré seriam A. falcatus e, com reservas, $A$. heterolepis.

Os Triportheidae e Characidae (Figs. 2A-K) são normalmente peixes pequenos, com tamanhos totais inferiores a $20 \mathrm{~cm}$, sendo o gênero Triportheus (Sardinha de água doce) o único gênero registrado de Triportheidae por Forline (1997), Piorski et al. (2003) e Castro e Dourados (2011) na região. No entanto, os gêneros Astyanax, Cheirodon, Bryconops, Poptella (identificados apenas por Castro e Dourados, 2011), Hyphessobrycon, Tetragonopterus e Charax (identificados apenas por Forline, 1997) foram registrados na região do sistema Pindaré/Alto Turiaçu/Caru. Por serem peixes de porte muito pequeno, podem não ter sido de grande interesse e poucos podem ter sido consumidos.

Os Curimatidae são peixes de porte pequeno a médio, muito comuns na região e tem sua distribuição em toda a América do Sul tropical. O gênero Curimata e, provavelmente, deva ter sido muito consumida pelos Awá-Guajá, contudo devido à semelhança dos ossos com os de outros peixes, seu reconhecimento é muito difícil.

Entre todos os peixes capturados pelos Awá-Guajá, as traíras (espécies Hoplias malabaricus e Hoplerytrhinus unitaeniatus, ambas da Família Erythrinidae) devem estar entre os mais facilmente reconhecíveis pela mandíbula e dentição (Figs. 2A-2F), que não somente exibem uma morfologia típica, mas também possuem características que auxiliam na sua preservação (Prestes-Carneiro et al. 2019). Foram duas espécies mais registradas na coleção e, apesar do número exato de exemplares ser discutível, é possível inferir com segurança que está entre os peixes mais pescados e consumidos pelos Awá-Guajá nesse período.

A família Hemiodontidae foi registrada por Forline (1997) na região a partir da espécie Hemiodus microlepis, porém não foi confirmada em estudos posteriores e a espécie observada na região foi Hemiodus argenteus (Castro e Dourado, 2011).

Os Prochilodontidae estão entre as famílias mais comuns da Amazônia Maranhense e, segundo Mota e Ruffino (1997), os Curimatã ou Curimbatá Prochilodus nigricans são um dos peixes mais capturados da Bacia Amazônica. Esses 
peixes provavelmente foram um dos mais consumidos pelos Awá-Guajá, porém, a exemplo de outras famílias de Characiformes, as escamas pequenas e frágeis tornam a identificação individual muito difícil.

A Família Serrasalmidae, é facilmente reconhecível na Coleção Guajá, devido às mandíbulas típicas das espécies dessa família (Figs. 2G-J). São reconhecidas na região a espécie Pygocentrus nattereri (Piranha Vermelha) e os gêneros Serrasalmus (Piranha Preta) (Figs. 2G-H) e pacus (Fig. 2I), além de espécies indeterminadas (Figs. 2J) (Forline, 1997 e Castro e Dourados, 2011).

Forline (1997) ainda cita a ocorrência da Familia Anostomidae, com as espécies Schizodon cf. dissimilis, Leporinus friderici e Pseudanos trimaculatus, cuja presença não foi confirmada em estudos zoológicos no Rio Pindaré por Castro e Dourados (2011). A presença de Schizodon dissimilis é comum na região Nordeste (Garavello e Britski 2019), Leporinus friderici foi observado no Rio Mearim e bacia do Rio Parnaíba no Estado do Maranhão (Soares, 2005; Ramos et al. 2014) e Pseudanos trimaculatus é um pequeno peixe $(12 \mathrm{~cm})$, que não foi observado na região e por isso sua ocorrência não pode ser confirmada.

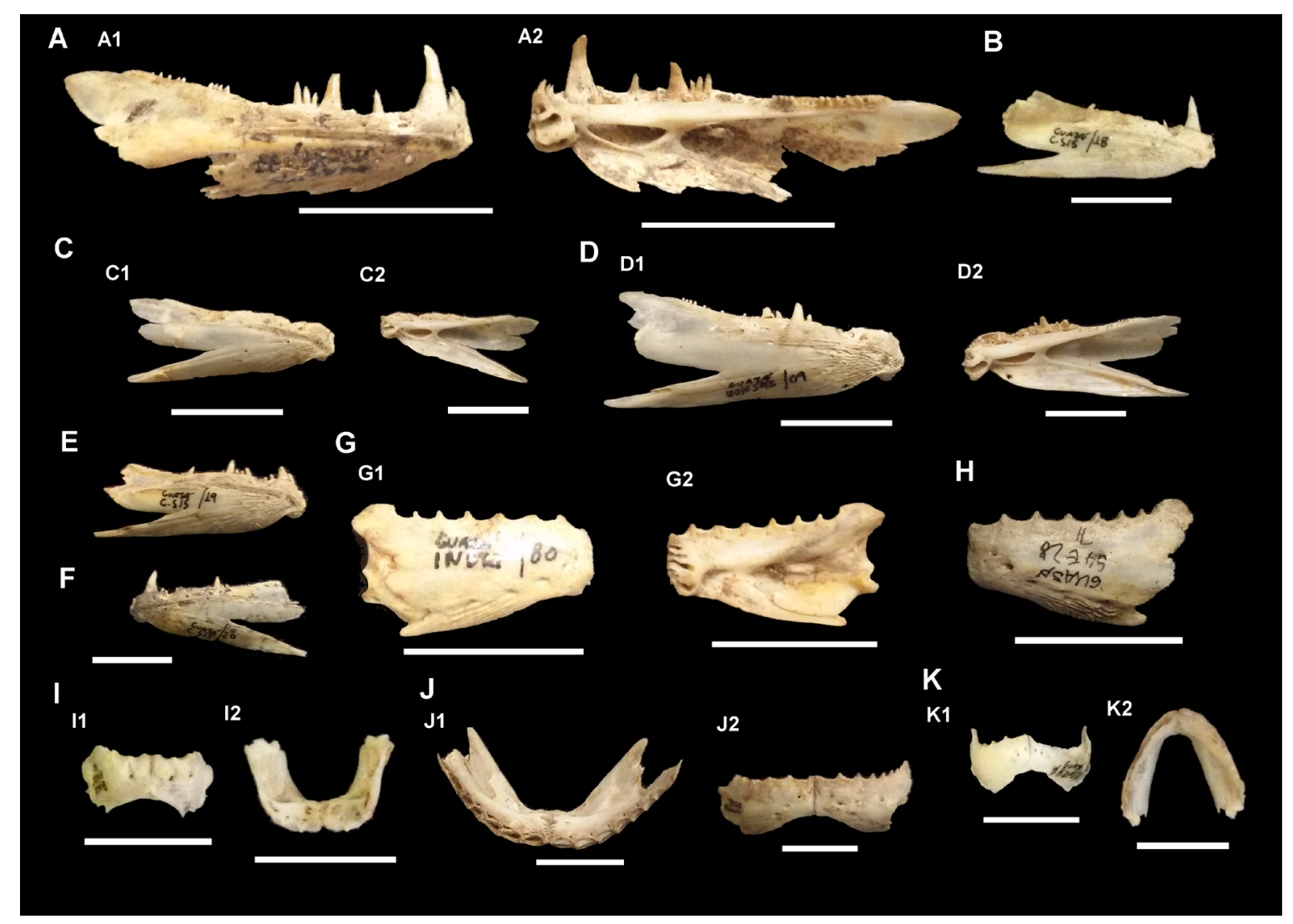

Figura 2. Mandíbulas de Characiformes. A-F) Erythrinidae, Hoplias sp. (Traíras), vistas laterais. G-J) Serrasalmidae. G - H) Vistas laterais de Serrasalmus sp. I) Mandíbula de Pacu, vistas frontal e oclusal respectivamente. J) Serrasalmidae indeterminado, vistas superior e frontal respectivamente. K) Characiformes indeterminado, vistas frontal e oclusal respectivamente. Escala $20 \mathrm{~mm}$. 


\section{Ordem Gymnotiformes}

Apesar de não termos na coleção, não é impossível que os Awá-Guajá possam ter capturado peixes dessa ordem, por serem comuns nos rios amazônicos. Segundo Forline (1997), quatro espécies de quatro famílias diferentes foram registradas: Gymnotus carapo, Rhamphichthys rostratus, Apteronotus albifrons e Sternopygus macrurus, porém ainda demandam confirmação.

\section{Ordem Siluriformes}

Popularmente conhecidos como bagres ou peixes-gato, os Siluriformes ocorrem em diversos ambientes dulcícolas e marinhos, e são facilmente reconhecíveis pelos espinhos nas nadadeiras. Além disso, em muitas espécies ocorrem espinhos, também conhecidos como "esporões" ou "acúleos" (Fig. 3A-D) nas nadadeiras peitorais e na primeira nadadeira dorsal. Os fragmentos cranianos também são resistentes e comuns na Coleção Etnográfica Guajá (Fig. 3 E-F). As famílias encontradas na região amazônica do Maranhão são: Aspredinidae, Auchenipteridae, Callichthyidae, Loricariidae, Doradidae e Pimelodidae (Castro e Dourados 2011).

Os Aspredinidae e Callichthyidae, não foram registrados por Forline (1997) em suas observações sobre a pesca entre os Awá-Guajá, porém a presença dessas famílias não deve ser completamente desconsiderada, dadas suas similaridades com outras. Os Callichthyidae são pequenos peixes-gato que poderiam ter sido alvo de pesca eventual pelos Awá-Guajá. Os Aspredinidae são conhecidos como peixe banjo (muitas vezes usados como peixes ornamentais) e possuem neurocrânio bastante resistente (fig. 4B), assim como espinhos pequenos (Fig. 3B).

A Família Doradidae são bagres de pequeno a médio porte que apresentam espinhos muito grandes nas nadadeiras dorsais e peitorais, com serrilhados comuns na parte anterior e posterior. Pelo menos dois desses espinhos foram registrados na Coleção Etnográfica Guajá (Fig. $3 \mathrm{C}$ ).

Os Auchenipteridae são representados pelos gêneros Auchenipterus, Pseudauchenipterus e Ageneiosus e a principal característica desta família é o robusto espinho localizado na nadadeira dorsal que pode ser muito grande e sinuoso (Fig. 3D) em relação ao tamanho do corpo. 


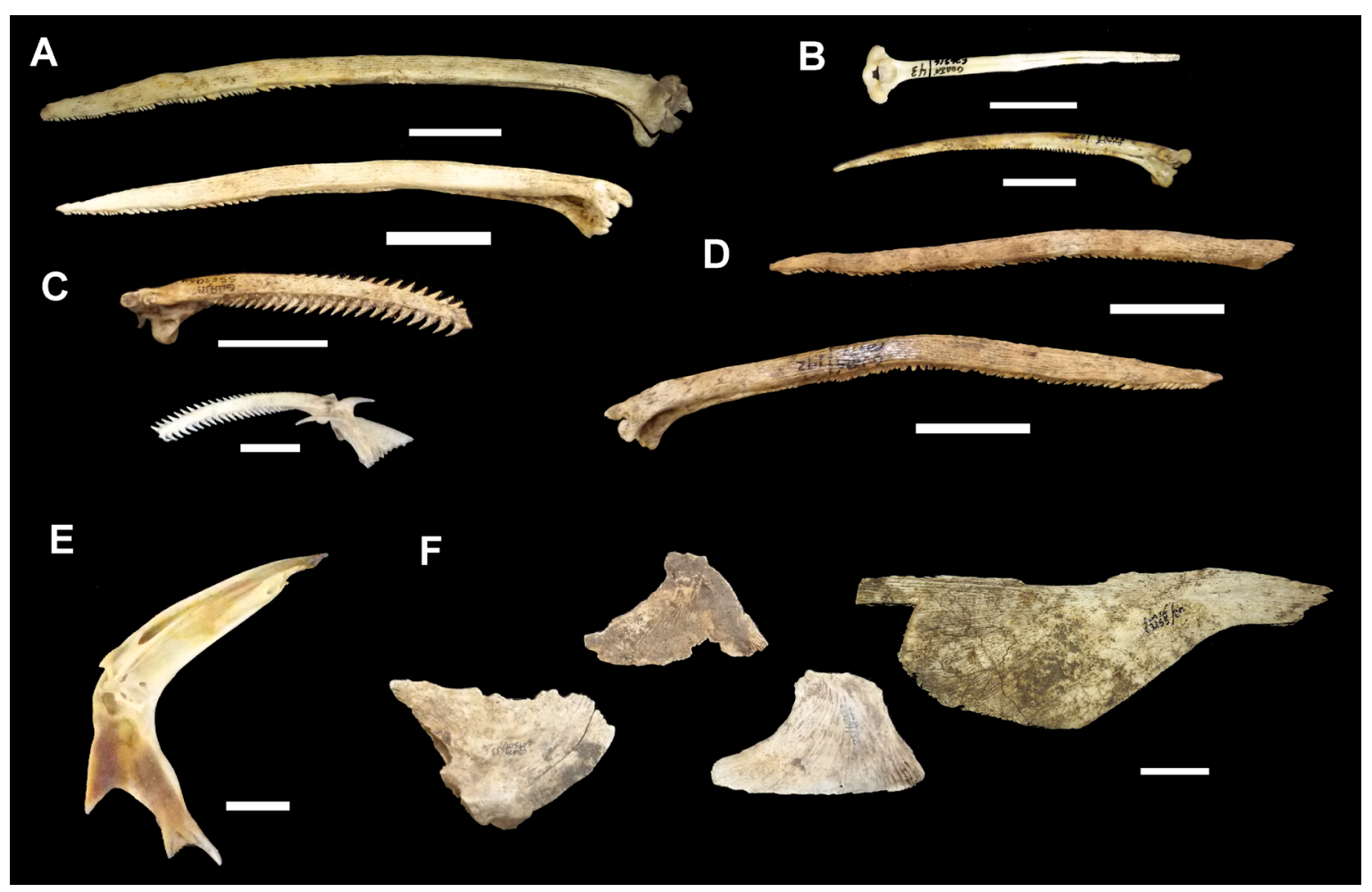

Figura 3. Espinhos de Pimelodidae (A) indeterminados; espécimes de médio porte indeterminados (B); Doradidae (C); Auchenipteridae, possível Ageneiosus (D); Cleitro de Pimelodidadae indeterminado (E); Opérculos e ossos cranianos indeterminados (F). Escala $20 \mathrm{~mm}$.

Os pequenos peixes (menores que $30 \mathrm{~cm}$ ) da família Loricariidae são conhecidos como "cascudos", e são muito comuns na América do Sul. Segundo FORLINE (1997), também foram capturados pelos Awá-Guajá, porém sua presença na Coleção Etnográfica Guajá é incerta, embora muitos pequenos neurocrânios (Fig. ${ }_{4}$ B) possam ser atribuídos tentativamente a essa família.

Os grandes bagres da família Pimelodidae são os maiores peixes da região (ultrapassando $50 \mathrm{~cm}$ em todas as espécies) e os que possuem as maiores partes ósseas preservadas da Coleção Etnográfica Guajá, representadas por neurocrânios e outros fragmentos cranianos (Fig. 4A). Um neurocrânio em bom estado de preservação pode ser útil para a identificação taxonômica em nível de espécie, como no caso do espécime da Figura 4-A6, atribuído a Pseudoplatystoma cf. fasciatum (Cachara, surubim).. 


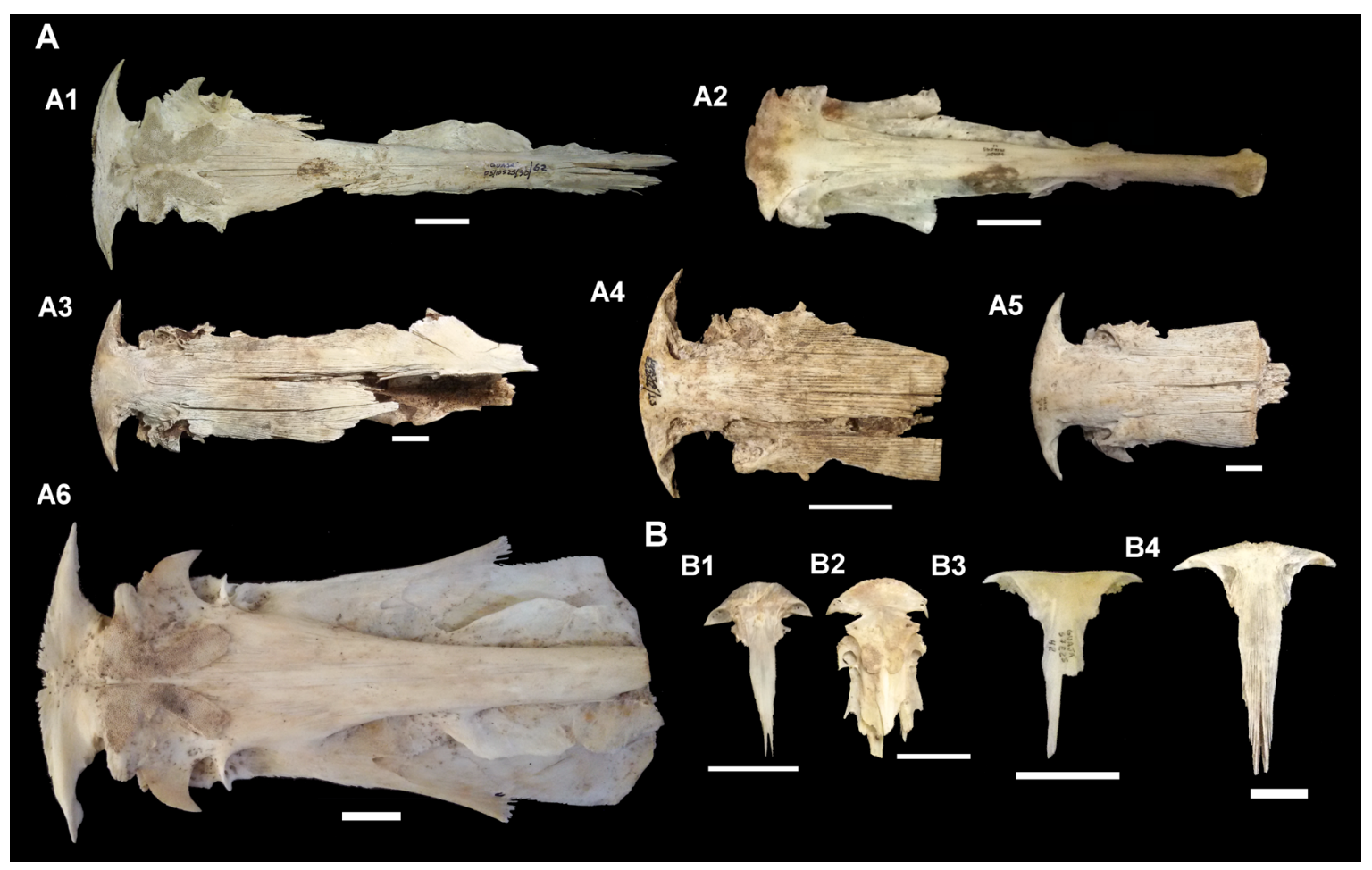

Figura 4. Neurocrânios de Siluriformes. A) Pimelodidae, A1-A5) espécies indeterminadas. A6) fragmento de neurocrânio de Pseudoplatystoma cf. fasciatum (Cachara); B)

Neurocrânios de pequenos Siluriformes. Escala 2omm.

\section{Outras ordens e espécies introduzidas}

As Ordens Carangiformes, Cichliformes e Perciformes possuem três famílias que foram registradas na Amazônia maranhense, cada uma representada por uma família; Centropomidae (Robalos), Cichlidae e Sciaenidae (pescada de rio da Amazônia), respectivamente. O Cichliformes tem reconhecimento difícil pela perda de dentes e características exclusivas, como espinhos e esporões, porém são muito comuns em todo o Brasil e os gêneros Crenicichla, Cichlasoma e Geophagus (Acará), muito comuns na região (Castro e Dourados 2011). Os Centropomidae foram apenas registrados no Rio Mearim, enquanto a espécie Plagioscion squamosissimus (Sciaenidae) foi observada na região das terras indígenas.

Castro e Dourado (2011) registram a presença na região de duas ordens, os Cyprinodontiformes, conhecidos comumente por tralhoto ou peixe de quatro olhos e representados pela espécie Anableps anableps, e os Synbranchiformes, representada pela espécie Synbranchus mamoratus, um pequeno peixe alongado usado como isca e conhecido como "muçum". Não existe evidência de espécimes dessas duas ordens terem sido capturados pelos Awá-Guajá.

Ainda, Forline (1997) observa na região a presença da Ordem Beloniformes, com a espécie Potamorrhaphis guianensis. Conhecido como peixe-agulha, é um 
peixe pequeno e muito alongado, que dificilmente seria confundido como outra espécie. No entanto, essa ocorrência não tinha sido observada anteriormente na região amazônica do Maranhão e a descrição supracitada amplia mais a ocorrência biogeográfica sugerida por Chagas e Barros (2018) para o Estado do Maranhão. Como a descrição de Forline (1997) é do final do século XX, não deve ser excluída a possibilidade de que a espécie não ocorra mais atualmente.

Outras espécies da Ordem Beloniformes foram registradas no Maranhão por Barros et al. (2011) com a espécie Strongylura marina para o rio Itapecuru e Ramos et al. (2014) que registraram Pseudotylosurus micros, para a Bacia do Parnaíba.

Castro e Dourados (2011) também citaram a presença de espécies introduzidas ou invasoras nos rios da Amazônia maranhense, sendo que no rio Pindaré ocorre a criação de peixes como o tucunaré (Cichla ocellaris), tilápia (Oreochromis spp.), tambaqui (Colossoma macropomum) e a carpa (Cyprinus carpio), sendo o tucunaré o mais comum.

\section{CARACTERIZAÇÃO TAFONÔMICA}

Concentrações ictiológicas, de origem natural (geralmente fluvial) ou de origem antrópica foram tema de estudos tafonômicos com vistas ao entendimento e reconstrução ecológica de ictiofaunas antigas e recentes (Behrensmeyer, 1991; Chahud e Petri, 2015; Prestes-Carneiro et al. 2019).

Em depósitos faunísticos recentes, datados dos tempos históricos, muitas vezes a origem antrópica dessa deposição é conhecida. Ainda assim, desde o momento do preparo da caça até a sua coleta pelos pesquisadores, passando pelo processamento e descarte desses materiais, os mesmos podem sofrer, além da ação humana, outras ações de cunho natural, incluindo a ação de fatores biológicos e climáticos. Desse modo, as informações aqui apresentadas poderão servir para comparação com depósitos encontrados em sítios arqueológicos mais antigos nas quais ocorrem restos ictiológicos.

O material ictiológico é um dos mais abundantes de toda essa coleção osteológica, representados por fragmentos cranianos (opérculos, cleitros, etc.) (Fig. $3 \mathrm{E}-\mathrm{F}$ ), vértebras (Figs. 5A-B), costelas, neurocrânios (Fig.4), vértebras complexas (Fig. $\left.{ }_{5} \mathrm{C}\right)$, mandíbulas, maxilas e espinhos de nadadeiras. O número de material identificado estaria próximo de 2488, porém muito material osteológico é indeterminado ou fragmentado.

$\mathrm{Na}$ comparação de elementos anatômicos observados entre as ordens identificadas, verifica-se que as mandíbulas e maxilas foram associadas aos Characiformes, mais especificamente, às famílias Characidae(Fig. 2) e Erythrinidae(fig. 2A-F). Já no caso da Ordem Siluriformes, os elementos usados para a identificação foram vértebras complexas, neurocrânios e espinhos (Figs. 3, 4 e 5C). Assim, a determinação do número de indivíduos por qualquer técnica clássica, como MNI (número mínimo 
de indivíduos) ou NISP (número de indivíduos determinado por espécime ósseo), apresenta limitações sérias e por não poderem ser utilizados critérios similares entre as ordens e grupos de peixes. A grande quantidade de material indeterminado e que pode pertencer a várias ordens de peixes, como vértebras pequenas e médias (Fig. $5 \mathrm{~A}$ ), também inviabilizam uma confiável determinação quantitativa.

Os restos de peixes encontrados na Coleção Etnográfica Guajá diferem na modificação óssea de outros grupos. Os outros vertebrados da coleção incluem aves, mamíferos (roedores, xenartros, ungulados, carnívoros e primatas) e répteis (cobras, lagartos, jacarés e quelônios) e todos apresentam indícios de algum tipo de seleção dos ossos, sendo mandíbulas, maxilas e partes cranianas as mais comuns (exceto em tartarugas e tatus nas quais os osteodermos são os elementos mais abundantes), ao passo que ossos pequenos e/ou frágeis, como costelas e vértebras, são menos abundantes. Nos mamíferos, répteis e aves dessa coleção, os ossos longos (fêmures, úmeros e tíbias) apresentam marcas de cortes ou estão fragmentados. Outro fator incomum nestes grupos é a articulação, apenas observada em algumas carapaças de quelônios e poucos ossos de aves que mantinham preservadas as partes moles. Já nos restos ictiológicos, espécimes pequenos e delicados são abundantes e a articulação é comumente observada em vértebras e costelas desses pequenos peixes (Fig. ${ }^{\mathrm{D}}$ ). Não foi observada evidência de seleção de tamanho dos ossos, assim como evidência de rachaduras, polimento ou desgaste causado por agentes físicos, como a variação térmica ou a exposição ao sol.

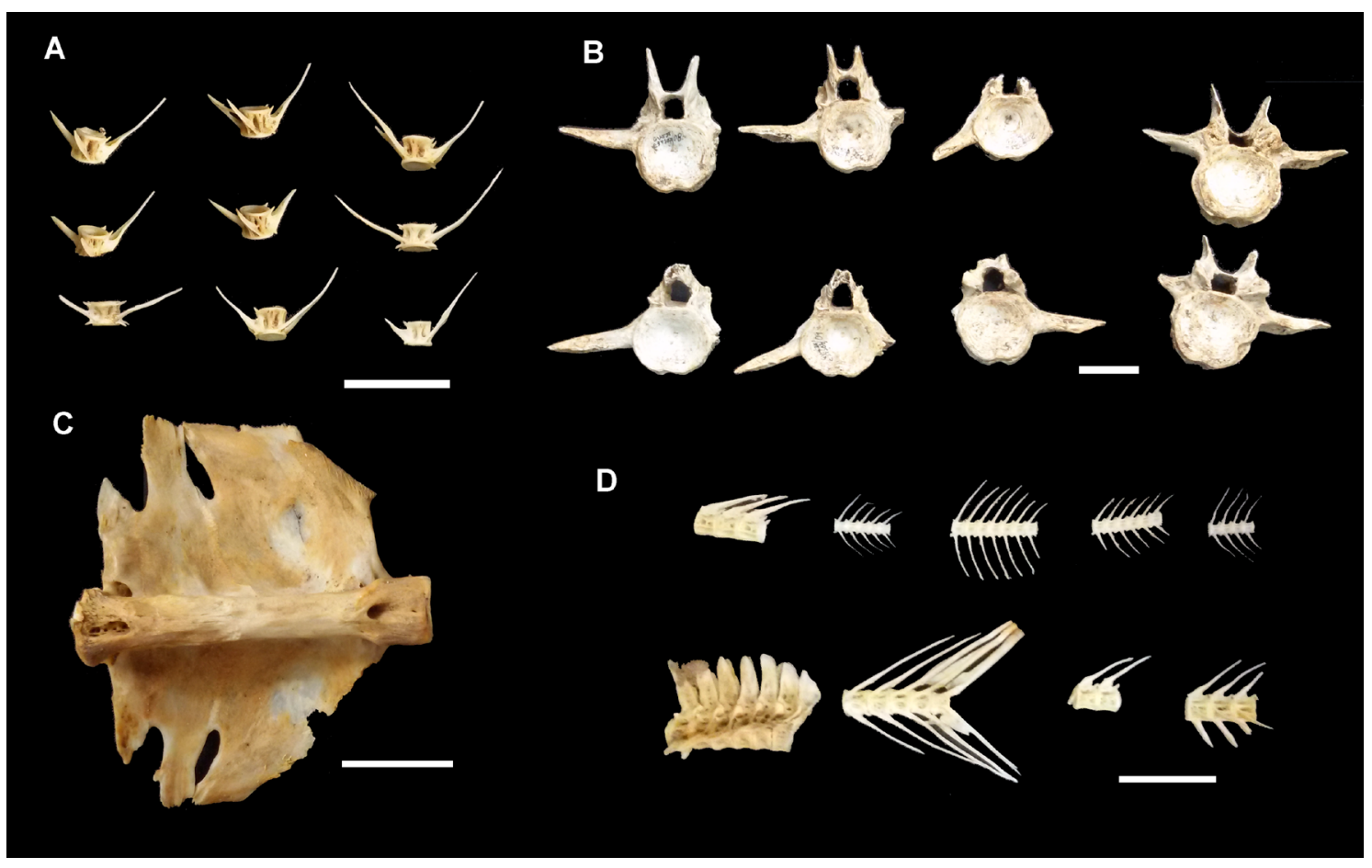

Figura 5. Vértebras e partes articuladas. A) Pequenas vértebras de Perciformes ou Siluriformes pequenos; B) Vértebras de Pimelodidae não identificado; C) Vértebra complexa de Pimelodidae; D) Partes articuladas de diversos peixes. Escala $20 \mathrm{~mm}$. 
Marcas de corte ou quebras associadas à preparação desses peixes para alimentação são observadas principalmente nos neurocrânios (Fig. 4) e nas vértebras complexas (Fig. ${ }_{5}$ C) de Siluriformes, devido ao fato da preparação incluir a retirada da cabeça de forma assertiva, resultando em cortes transversais e quebras perimortem (figuras 4A3-4A6). A queima dos ossos foi observada em menos de 10 peças ósseas, e não representa um dado significativo.

\section{COMENTÁRIOS SOBRE A PRESERVAÇÃO DE REMANESCENTES ICTIOLÓGICOS EM SÍTIOS ANTIGOS}

Os estudos ictiológicos de partes desarticuladas, como é o caso da maioria dos remanescentes analisados nesse trabalho, fornecem poucas informações que possibilitam a identificação segura de espécies, porém as partes preservadas podem ser diagnósticas de diversas ordens e famílias. Para isso, é necessário um conhecimento profundo da anatomia e, se possível, um conhecimento prévio da biodiversidade local.

O conhecimento da idade da deposição e as condições ambientais locais da mesma são muito importantes para a preservação de espécimes com partes identificáveis. Um caso de sítio arqueológico no qual foram encontrados muitos fragmentos de ictiofauna preservada é o de Llanos de Mojos, na Bolívia. Nesse sítio, datado entre os anos de 500 e $1400 \mathrm{AD}$ apesar da presença de inundações alternadas por períodos de seca prolongada, houve a preservação de muitos fragmentos ictiológicos nos níveis mais profundos do solo, que estavam protegidos das intempéries (Prestes-Carneiro et al. 2019). Por outro lado, climas mais áridos ou de soterramento rápido podem preservar grande quantidade de material de vários tipos em todas as camadas, como observados em fragmentos de peixes da Formação Irati do início do Permiano (aproximadamente 280 milhões de anos) do Brasil, nas quais o material osteológico foi preservado no fundo de um grande corpo de água (Chahud e Petri, 2015). Embora exista uma diferença considerável em termos da amplitude temporal observada nos depósitos que geraram a Coleção Etnográfica Guajá, as acumulações faunísticas de Llano de Mojos e a Formação Irati, é importante pensar na importância dos fatores ambientais que permitem a preservação a curto, médio e longo prazo de remanescentes faunísticos.

Tanto em sítios paleontológicos quanto em sítios arqueológicos, determinadas partes ósseas têm maior facilidade de preservação. Entre essas, é possível destacar vértebras, espinhos, escamas variadas, placas dérmicas, placas dentárias, dentes e algumas partes articuladas (Chahud e Petri, 2015; Prestes-Carneiro et al. 2019).

Os depósitos faunísticos que resultaram na Coleção Etnográfica Guajá ocorrem em ambiente úmido e quente e a decomposição pode ser acelerada por essas condições. Comparando com sítios arqueológicos da América do Sul nas quais há evidência de atividade pesqueira em água doce, os espécimes da Coleção apresentam 
grandes vértebras de Siluriformes e Characiformes com processos laterais ainda preservados, ao contrário do observado na maior parte das vértebras encontradas na Lapa do Santo (MG), na qual verifica-se a presença apenas da parte central dessas vértebras (Mingatos, 2017 e Mingatos e Okumura, 2016), Llanos de Mojos (PrestesCarneiro et al. 2019) ou mesmo em sambaquis (Bandeira et al. 2016).

O tamanho dos espécimes em sítios arqueológicos, tanto em depósitos de descarte como em sambaquis (Bandeira et al. 2016; Mingatos e Okumura, 2016; Prestes-Carneiro et al. 2019) é, em média, muito menor do que os encontrados na Coleção Etnográfica Guajá, no entanto isso não é indicativo de que povos antigos capturavam apenas peixes menores, pois, como observado nas figuras $5 \mathrm{~A},{ }_{5} \mathrm{~B}$ e ${ }_{5} \mathrm{D}$, as vértebras menores possuem tendência de preservar os processos laterais $\mathrm{e}$ articulações por mais tempo do que espécimes maiores. Uma possibilidade para isso ocorrer é que o material menor seria mais facilmente descartado e estaria menos exposto a atividades que potencialmente diminuíssem sua preservação, como pisoteio, preparação para o consumo e ataques de carniceiros.

Os espinhos de Chondrichthyes (raias) e de Siluriformes (bagres e peixes-gato) podem ser encontrados em sítios arqueológicos (Bandeira et al. 2016; Gonzalez, 2005; Koole, 2014) e, assim como acontece com as vértebras, esses espinhos encontrados em sítios arqueológicos geralmente encontram-se fragmentados (Bandeira et al. 2016; Mingatos e Okumura, 2016; Prestes-Carneiro et al. 2019), preservando apenas as partes distais ou proximais articulatórias (mais densas e resistentes), sendo que raramente espinhos completos são preservados.

Os neurocrânios e fragmentos cranianos que ocorrem com freqüência na Coleção Etnográfica Guajá não são muito observados em sítios arqueológicos e os motivos podem ser os mais variados, incluindo o fato de ser um material de tamanho relativamente grande, mais frágil do que dentes e espinhos, passando pela possibilidade de descarte da cabeça de grandes espécimes em local diferente daquele no qual o restante do peixe era processado e posteriormente descartado.

\section{CONSIDERAÇÕES FINAIS}

De modo geral, é possível propor que a pesca realizada pelos Awá-Guajá na segunda metade do século XX não levava em consideração espécies ou tamanho dos peixes que eram capturados. A análise realizada na Coleção Etnográfica Guajá (Figs. 4B e 5D), as observações de Forline (1997) e os registros na região feitos por Castro e Dourado (2011) mostra que muitos espécimes eram pequenos ou médios, não superando $20 \mathrm{~cm}$ de comprimento total.

A pesca em grande quantidade feita por redes ou pela utilização de venenos de peixe (timbó), descritas por Forline (1997), podem ter sido as responsáveis pela captura de pequenos peixes. O preparo desses não implicou em grandes modificações 
da estrutura original do peixe, uma vez que é possível verificar a presença de peixes com as vértebras centrais ainda articuladas na Coleção Etnográfica Guajá.

Um fator importante a ser considerado é o clima úmido da região onde se localiza a Terra Indígena Caru, que possui considerável diferença pluviométrica entre os meses mais secos e os mais úmidos. Felizmente, dado o curto período que se passou entre o descarte do material e sua escavação, os fatores ambientais não afetaram em demasia a preservação dos materiais. Prova disso é a presença de quantidade considerável de material frágil, como finas costelas, e de material ósseo articulado que se preservou, apesar das mudanças de temperatura sazonais, do pisoteamento e do potencial ataque de carniceiros.

O relativamente bom estado de preservação do material ictiológico demonstra que o intervalo entre sua deposição após o consumo e a escavação do mesmo teria sido curto, não sendo suficiente para sua dispersão por eventos pluviais do período chuvoso ou por ação de necrófagos ou coletores. Outro fator que pode ter sido importante para a preservação desses materiais é o fato de que peixes são os animais mais capturados nos períodos secos (Forline, 1997; Prado et al. 2012), época na qual também foram feitas as coletas.

\section{AGRADECIMENTOS}

Agradecemos ao Renato Kipnis pelas ricas discussões sobre os materiais faunísticos coletados por ele e por Helder Queiroz na Terra Indígena Caru, entre 1987 e 1990, e que atualmente compõem a Coleção Etnográfica Guajá. Agradecemos o apoio financeiro dado a MO: Bolsa Produtividade CNPq (302163/2017-4) e Auxílio Jovem Pesquisador Fapesp (2018/23282-5).

\section{REFERÊNCIAS}

Barros MC, Fraga EC, Birindelli JLO. 2011. Fishes from the Itapecuru River basin, state of Maranhão, northeast Brazil. Brazilian Journal of Biology. 71(2):375-38o. https:// doi.org/10.159o/S1519-69842011000300006

Bandeira AM, Chahud A, Ferreira, ICP, Pacheco MLAF. 2016. Mobilidade, subsistência e apropriação do ambiente: contribuições da zooarqueologia sobre o Sambaqui do Bacanga, São Luís, Maranhão. Boletim do Museu Paraense Emílio Goeldi. Ciências Humanas, 11(2):467-480.

Behrensmeyer AK. 1991. Terrestrial vertebrate accumulations. In: Allison, PA e Briggs DEG. (eds.), Taphonomy: releasing the data Locked in the fossil record. Plenum Press, New York. 291- 327. 
Bissaro-Junior M. 2008. Tafonomia como ferramenta zooarqueológica de interpretação: viés de representatividade óssea em sítios arqueológicos, paleontológicos e etnográficos. Dissertação de Mestrado. Instituto de Biociências, USP. 102 p.

Castro ACL e Dourado ECS. 2011. Ictiofauna da Amazônia Oriental Brasileira - um panorama das regiões maranhenses. In: Martins MB e Oliveira TG (Eds) Amazônia Maranhense: diversidade e conservação. MPEG, Belém. 195-202.

Chagas RA e Barros MRF. 2018. Increased geographical distribution of Potamorrhaphis guianensis (Jardine, 1843) (Beloniformes: Belonidae) in the Brazilian Amazon Region. Brazilian Journal of Biological Sciences, 5(11): 627-630.

Chahud A. 2019. Uma coleção osteológica de roedores derivada de atividades de caça da Sociedade Awá-Guajá do Estado do Maranhão. Acta Biologica Catarinense. 6(4): 83-94.

Chahud A. 2020a. Presença de duas espécies de Caimaninae (Crocodylia, Alligatoridae) em material osteológico oriundo de descarte da comunidade Awá-Guajá no Estado do Maranhão. Revista Nordestina de Zoologia, 12(2), 15-25.

Chahud A. 202ob. Uma coleção de Carnívora derivada de atividades de caça da Sociedade Awá-Guajá do Estado do Maranhão, Brasil. Biota Amazônia, 10(2), 34-37.

Chahud A e Petri S. 2015. Geology and Taphonomy from the Base of the Taquaral Member, Irati Formation (Permian, Paraná Basin), Brazil. Acta Geologica Polonica, 65(3):379-387.

Forline LC. 1997. The persistence and cultural transformation of the Awá-Guajá indians: foragers of Maranhão state, Brazil. Tese de Doutorado em Antropologia. University of Florida, Gainesville. 336p.

Garavello JC e Britski HA. 2019. Redescription of Schizodon dissimilis and appraisal of the dark barred species of the genus (Characiformes: Anostomidae). Neotropical Ichthyology, 17(3):e18oo35.

Gonzalez MDCP. 2015. Estudo taxonômico das espécies de Acestrorhynchus do grupo lacustris, e atualização dos dados de distribuição geográfica de todas as espécies do gênero, para os rios brasileiros. Dissertação de Mestrado, Instituto de Biociências da Universidade de São Paulo, São Paulo. 153p.

Gonzalez MMB. 2005. Tubarões e Raias na Pré-História do Litoral de São Paulo. Tese de Doutorado em Arqueologia. Museu de Arqueologia e Etnologia, Universidade de São Paulo, São Paulo. 323p. 
Koole EKM. 2014. Entre as tradições planálticas e meridionais: Caracterização arqueológica dos grupos caçadores coletores a partir da análise de sete elementos e suas implicações para a ocupação pré-cerâmica da Região Cárstica do Alto São Francisco, Minas Gerais, Brasil: Cronologia, tecnologia lítica, subsistência (fauna), sepultamentos, mobilidade, uso do espaço em abrigos naturais e arte rupestre. Tese de doutorado, de Arqueologia e Etnologia, Universidade de São Paulo, São Paulo. 564p.

Mingatos GS. 2017. Caça ou deixa passar? A dieta dos grupos humanos do sitio Lapa do Santo? Lagoa Santa-Minas Gerais. Dissertação de Mestrado em Arqueologia. Universidade Federal do Rio de Janeiro. 88p.

Mingatos GS e Okumura M. 2016. Modelo de Amplitude de Dieta aplicada a restos faunísticos do sítio Lapa do Santo (MG) e suas implicações para o entendimento da dieta em grupos Paleoíndios do Brasil central. Palaeoindian Archaeology, 1:15-31.

Mota, SQ e Ruffino, ML. 1997. Biologia e pesca do curimatã (Prochilodus nigricans Agassiz, 1829) (Prochilodontidae) no médio Amazonas. UNIMAR, 19(2):493-508.

Piorski NM, Castro ACL, Pinheiro CUB. 2003. A Prática da Pesca entre grupos indígenas das bacias dos rios Pindaré e Turiaçu no estado do Maranhão, nordeste do Brasil. Boletim do Laboratório de Hidrobiologia, São Luis, 16:67-74.

Prado HM. 2007. O impacto da caça versus a conservação de primatas numa comunidade indígena Guajá. Dissertação de Mestrado em Ecologia de Ecossistemas Terrestres e Aquáticos. Instituto de Biociências. Universidade de São Paulo, São Paulo. 98p.

Prado HM, Forline LP, Kipnis R. 2012. Hunting practices among the Awá-Guajá: towards a long-term analysis of sustainability in an Amazonian indigenous community. Boletim do Museu Paraense Emílio Goeldi. Ciências Humanas, Belém, 7(2): 479-491.

Prestes-Carneiro G, Béarez P, Shock MP, Prümers H, Betancourt CJ. 2019. Pre-Hispanic fishing practices in interfluvial Amazonia: Zooarchaeological evidence from managed landscapes on the Llanos de Mojos savanna. Plos one. 14 (5): 1-29

Queiroz HL e Kipnis R. 1990. Os índios Guajá e os primatas da Amazônia maranhense: um caso de sustentabilidade de caça. A Primatologia no Brasil. 5:81-94.

Ramos, TPA, Ramos, RTDC, Ramos, SAQ. 2014. Ichthyofauna of the Parnaíba river basin, northeastern Brazil. Biota Neotropica. 14(1): e20130039. https://doi.org/10.159o/ S1676-06020140039 
Reschke GA, Eloi CMA, Silva RM. 2011. Caracterização climática da Amazônia maranhense. In: Martins MB e Oliveira TG (Eds) Amazônia Maranhense: diversidade e conservação. MPEG, Belém, p.47-70.

Silva AT e Goitein R. 2009. Diet and feeding activity of Acestrorhynchus lacustris (Lütken, 1875) (Characiformes, Acestrorhynchidae) in the water reservoir at Ribeirão Claro, SP. Brazilian Journal of Biology. 69(3):757-762.

Soares EC. 2005. Peixes do Mearim. São Luís: Instituto Geia. 143 P.

Thornthwaite CW. 1948. An approach toward a rational classification of climate. Geographical Review, 38(1): 55-94. 